doi:10. $18575 / \mathrm{msrs} .9 m .3 .16 .07$

UDK: 616-7:004.41

ORIGINALNI RAD
COBISS.RS-ID: 5699096

\title{
Ispitivanje stabilnosti osteosintetskog materijala softverskim simulatorom kosti
}

\section{SAŽETAK}

Uvod. Softverski model simulatora (SCA) je računarski program pisan na jednom od mnogobrojnih programskih jezika. Na osnovu zadanih ulaznih podataka na matematičkom biomehaničkom modelu kosti i na modelima raznih osteosintetskih materijala, on izračunava i daje tražene izlazne rezultaze o diletaciji (mm) na mjestu preloma u odnosu na primjenjenu aksijalnu i bočnu silu (N).

Cilj rada. Istražiti proračun napona i deformaciju na sile pritiska i savijanja na simulatoru softverskog modela kod dinamičko kompresivne ploče (DCP), dinamičko kopresivne zaključane ploče (LCP), intermedularnog zaključanog klina (LIN) i unutrašnjeg fiksatora po Mitkoviću (IFM).

Ispitanici i metode. Za izradu 3D modela DCP, LCP, IFM, LIN,korišten je softver CATIA, a za proračun napona i deformacija za pritisak i savijanje, softver ANSYS(SCA). Ispitivani materijal opterećen je silama kompresije do $500 \mathrm{~N}$ i silama savijanja do $250 \mathrm{~N}$.

Rezultati istraživanja. Rezultati biomehaničkog ispitivanja na SCA pokazuju da je, po biomehaničkoj stabilnosti, na prvom mjestu LIN sa koeficijentom ranga $\mathrm{KLIN}=0,1950$. Zatim slijede DCP sa KDCP=0,1970, IFM sa KIFM=0,2238 i LCP sa $\mathrm{KLCP}=0,2394$.

Diskusija. Na osnovu ulaznih podataka, formira se matematički model koji korištenjem unesenih podataka izračunava i edituje tražene rezultate. U svijetu je danas tendencija da se napravi standarizacija softverskog ispitivanja, kako bi se ispitivani rezultati mogli jednostavno primjenjivati i tumačiti u naučno-istraživačke svrhe.

Zaključak. Prvi u rangu po biomehaničkoj stabilnosati je LIN, sa koeficijentom ranga $\mathrm{KLIN}=0,1950$. Zatim slijede $\mathrm{DCP}$ sa $\mathrm{KDCP}=0,1970$, IFM sa $\mathrm{KIFM}=0,2238 \mathrm{i}$ LCP sa KLCP=0,2394.

Ključne riječi: biomehanika, dinamičko kompresivne ploče, softver CATIA i ANSYS.

(Scr Med 2016:47:42-48)

Predrag Grubor,"

Rade Tamjga, ${ }^{2}$

Milan Grubor,

\section{Đeri Jugoslavi}

${ }^{1}$ Klinika za Traumatologïu UMC

Banja Luka

${ }^{2} Z U$ "Dr Grubor"

${ }^{3}$ Klinika za opštu i abdomenalnu

hirurgïu, UMC Banja Luka

\section{Kontakt adresa:}

Predrag Grubor, Ul. Aleja Svetog Save 20/24

78.ooo Banja Luka

Republika Srpska

Bosna i Hercegovina

E-mail:predraggrubor@gmail.com

$M o b++38765513115$

Rad primljen: 11.1.2016. Rad prihvaćen: 31.1.2016. 


\section{Uvod}

Danas postoje brojne unutrašnje i spoljašnje metode stabilizacije preloma. Nakon hirurškog pristupa prelomu, za unutrašnju stabilizaciju koristi se osteosintetski implantat kojim se stabilizuje prelom kosti. Implantati se izrađuju od posebnih bioinertnih metala koji ne dovode do komplikacija uslijed nekompatibilnosti sa tkivom. Danas se koriste implantati dizajnirani tako da svojom konstrukcijon minimalno oštećuju vaskularizaciju kosti i narušavaju integritet periosta. ${ }^{1{ }^{2}}$

Osteosintetski materijali s kojima se najčešce radi interna fiksacija su sljedeći: dinamičko-kompresivna ploča (DCP), kompresivna ploča sa zaključavanjem (LCP), interni fiksator Mitković (IFM) i intramedularni zaključani klin(LDN).

DCP ina specijalno dizajniran oblik otvora za vijke, čijim pritezanjem primiče fragmente jedan prema drıgom i tako omogućava postizanje aksijalne kompresije. Otvor za vijak omogućava implantaciju vijka pod uglom i do $25^{\circ} .^{2}$

LCP ploča ima otvore za vijke slične DCP ploči, ali je s jedne strane пагеzan паvoj otvora za vijak koji ne dozvoljava aplikaciju istog pod uglon. LCP ploča onogıcava postavljanje kako standardnih vijaka sa sferičnom glavom, tako i novorazvijenih sigurnosnih vijaka sa glavom koja se ureže $\mathbf{i}$ ukliješti u otvore za vijak u ploče. ${ }^{3}$ LCP ploča omogıćava kombinaciju standardnih vijaka sa sferičnom glavon i vijaka sa glavom koja se ureže što bolje spriječava razlabljivanja između vijaka i ploče nego u slučaju DCP. vijci uklješteni u ploču daju stabilnost i nema potrebe da ploča leži na kosti. ${ }^{2,3}$

IFMse plasira uz kost bez deperiostiranja fragmenata i sa minimalnim oštećenjem mekog tkiva. Ina četiri pokretne kleme koje klize duž nosača. Nosač je $1 \mathrm{~mm}$ odmaknut od periosta. Kleme se fiksiraju vijcina u više ravni. Na tim mjestima jedino unutarnji fiksator ima kontakt sa periostom dijafize. vijci su proksimalno i distalno na nosaču. Distalno postavljen vijak omogućava spontanu dinamizaciju. ${ }^{4}$ Ovako se postiže stabilnost fragmenata i mir u žarištu preloma. Sa vertikalizacijon bolesnika, proksimalni fragment putuje ka distalnom vršeći kompresiju među fragmentima u žarištu prelona i tako pospješuje proces osteogeneze. (Slika 1.)
Slika 1. Softverski model internog fiksatora po Mitkoviću

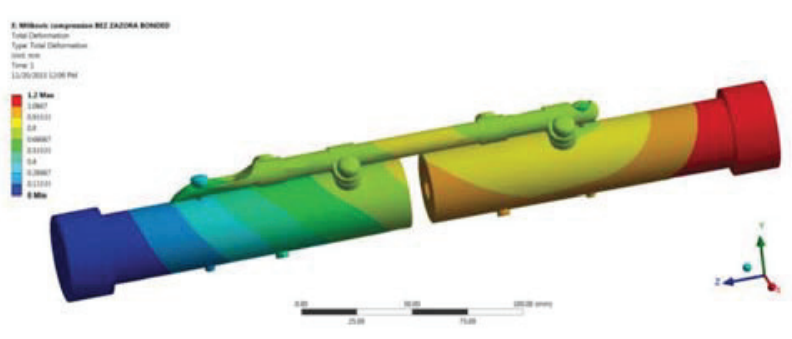

LDN treba biti dowoljno debeo da bi se postigla stabilпа osteosinteza, a vijakna kraju klina učvršćuje isti пa korteksu čime se sprječavaju rotacioni, torzioni pokreti među koštanim fragmentima.

Osim bioloških faktora u sanaciji preloma, biomehanički uticaj je presudan u hisogenezi i sazrijevanju kalusa. Prelomljena kost izložena je vrlo složenom spregu gravitacionih, inercionalnih i mišićnih sila. Zbog toga, mjesto preloma je konstantno izloženo silama kompresije, dekompresije, savijanja i torzije.To je razlog da u području prelomne pukotine postoje različita naprezanja. Koja je tačna veličina diletacije za zarastanje nije još jasno definisano, ali većina autora smatra da ne bi trebala da prelazi $1 \mathrm{~mm} .{ }^{1-5}$ Izbor osteosintetskog materijala za stabilizaciju preloma jedan je od bitnihı uslova za sanaciju kosti.5.5

\section{Cilj rada}

Istražiti proračın napona i deformaciju na sile pritiska i savijanja na simulatoru softverskog modela kod DCP, LCP, LIN, IFM. Istraživanjem doći do saznanja koji od ispitivanih osteosintetskih imlantata na softverskim modelima ima najbolje biomehaničke karakteristike za stabilizaciju prelona.

\section{Materijali metode}

Za izradu 3D modela korišćen je softver CATIA, a za proračun napona i deformacija za pritisak i savijanje softver ANSYS. Analiza napona i deformacija rađena je analizom finite element analysis (FEA). Ispitani osteosinteski materijal opterécen je silama kompresije do $500 \mathrm{~N}$, a silama savija nja do 250 N. Pratili smo i silu deformacije koja se javljala usljed dejstva sile kompresije i savjanja, na osnovu čega smo procijenjivali stabilnost.

Za eksperimentalnoispitivanje koristilisu se geometrijski identični, anatonski oblikovani modeli prečnika $30 \mathrm{~mm}$, dužine $100 \mathrm{~mm}$ sa prelomnom pukotinom od $10 \mathrm{~mm}$.U softverski program unesene su vrijednosti: elastičnost, visokoelastičnost,plastičnost, čvrstoća, tvrdoća, žllavost, 
vibracija i torzija kosti. Ovakvi modeli omogućuju identične biomehaničke uslove za sva ispitivanja ispitivanog osteosintetskog materijala. (Slika 2.)

Slika.2. Softverski model intermedularnog zaključanog klina- ispitivanje bočnih sila

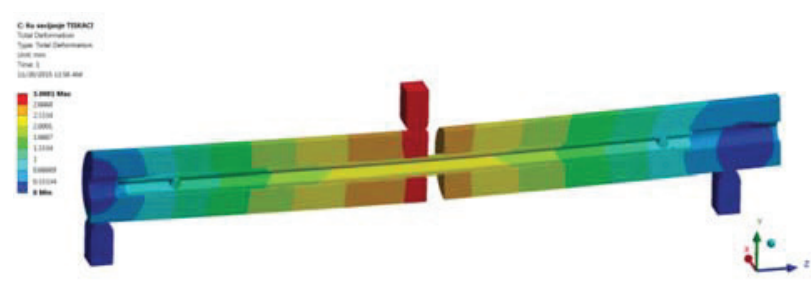

Rangiranje raznih osteosintetskih materijala DCP,LCP, LIN i IFM vršeno je posebno za ispitivanja na SCA. Rangiranje je vršseno određivanjem minimalnog koeficijenta ranga, na osnovu aritmetičke sredine (srednja vrijednost) diletacije u milimetrima, za slıčaj različitih težinskih koeficijenata aritmetičkih sredina i to: težinski koeficijent za pritisak $\mathrm{K}_{\mathrm{P}}=0,5$; težinski koeficijent za savijanje u jednoj ravni $\mathrm{K}_{1}=0,25$; težinski koeficijent za savijanje u drugoj ravni $\mathrm{K} 2=0,25$. Koeficijent ranga za svaki od ispitivanih osteosintetskih materijalana SCA Simulatoru određen je prema sljedećem algoritmu:

$K_{i}=\operatorname{Min}_{i}\left(K_{p} * \overline{X_{p}}+K_{1} * \overline{X_{1}}+K_{2} * \overline{X_{2}}\right)$

gdje je:

- Ki - koeficijent ranga pojedinog osteosintetskog materijala;

- i - LDN; DCP; LCP; IFM oznaka osteosintetskog materijala;

- $X_{P}$ - aritmetička sredina diletacije (mm) za silu pritiska;

- $\quad \underline{\mathrm{K}}_{\mathbf{p}}-$ koeficijent sile pritiska;

- $\bar{X}_{1}$ - aritmetička sredina diletacije (mm) za silu savijanja u jednoj ravni;

- $\quad$ K1 - koeficijent sile savijanja u jednoj ravni;

- $\quad X_{2}$ - aritmetička sredina diletacije (mm) za silu savijanja u drugoj ravni;

- K2 - koeficijent sile savijanja u drugoj ravni;

\section{Rezultati}

Ispitivani osteosinteski materijal opterećen je silama kompresije do $500 \mathrm{~N}$, a silama savijanja do $250 \mathrm{~N}$. Praćena je veličina diletacije (deformacije) u milimetrima u zavisnosti od dejstva sile kompresije(Grafikon 1.)i sila bočnih savijanja.(Grafikon 2.)
Grafikon 1. Distribucija sile kompresije (N) u odnosu na diletaciju $(\mathrm{mm})$ ispitivana na SCA Simulatoru na silu kompresije.

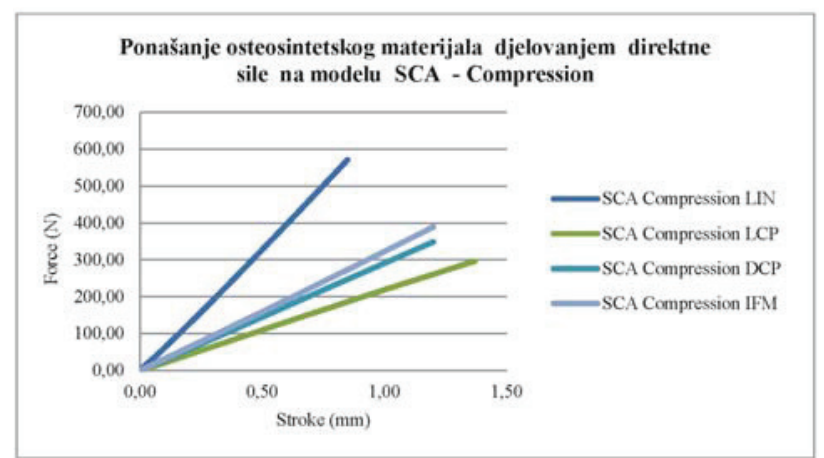

Grafikon 2.Distribucija sile savijanja (N) u odnosu na diletaciju $(\mathrm{mm})$ ispitivana na SCA simulatoru

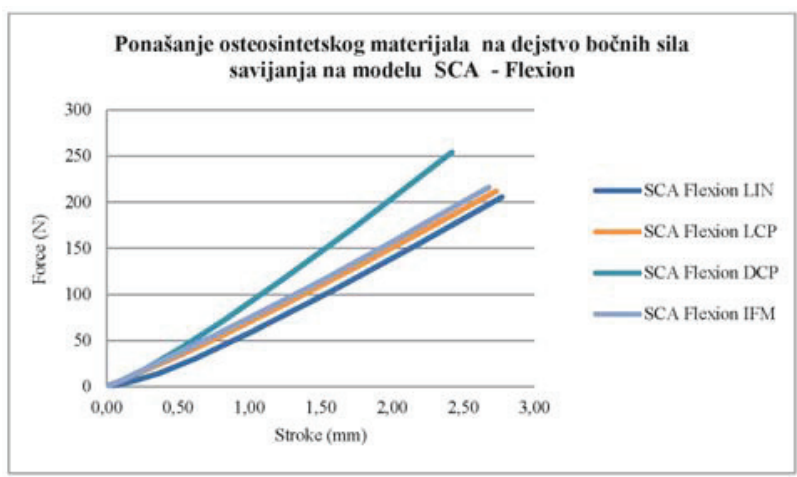

Na osnow težinskih koeficijenata sila: pritisak $\mathrm{K}_{\mathrm{P}}=0,5$; savijanje u jednoj ravni $\mathrm{K}_{1}=0,25$; savijanje u drugoj ravni $\mathrm{K} 2=0,25$ dobijen je rang biomehaničke stabilnosti ispitivanih osteosintetskih materijala. Kao mjera biomehaničke stabilnosti usvojena je aritmetička sredina diletacije ispitanog osteosintetskog materijala u odnosu na silu. (Tabela 1.)

Tabela 1. Rezultati ispitivanja na SCA simulatoru softverom CATIA i ANSYS

\begin{tabular}{ccc}
\hline $\begin{array}{c}\text { Redos- } \\
\text { lijed }\end{array}$ & $\begin{array}{c}\text { Osteosintetski materijal ispitan } \\
\text { na SCA Simulatoru }\end{array}$ & Koeficijent zbira \\
\hline 1 & LIN & 0,1950 \\
\hline 2 & DCP & 0,1970 \\
\hline 3 & IFM & 0,2238 \\
\hline 4 & LCP & 0,2394 \\
\hline
\end{tabular}

Iz Tabele 1.vidjivo je da je prvi u rangu po biomehaničkoj stabilnosti LIN sa koeficijentom ranga KLIN $=0,1950$. Zatim slijede DCP sa KDCP $=0,1970$, IFM sa KIFM $=0,2238$ i LCP sa KLCP $=0,2394$. 


\section{Diskusija}

SCA Simulator(softver) je računarski program pisan na jednom od mnogobrojnih programskih jezika. On obraduje zadane ulazne podatke te izračunava srednje $\mathbf{i}$ daje tražene izlazne rezultate. U nekin slučajevina, kada se ne posjeduje orginalan matematičko-kompjuterski simulator, a u zavisnosti šta se ispituje, može da posluži i sličan softverski program. Na osnovu ulaznih podataka formira se matematički model koji korištenjem unesenih podataka izračunava i edituje tražene rezultate. Danas u svijetu postoji tendencija da se napravi standarizacija softverskog ispitivanja kako bi se ispitivani rezultati mogli jednostavno primjenjivati i tumačiti u naučno-istraživačke svrhe. ${ }^{7}$ Nekada se koristila unutrašnja fiksacija s pločon kojom se postizala apsolutna stabilnost slomljenih koštanih fragmenata koja nije dozvoljavala mikropokrete između fragmenata. Takva stabilizacija preloma znala je rezultirati labavljanjem implantata $\mathbf{i}$ odložnim zarastanjem ili nezarastanjem kosti.7

Maksinalno opterećenje koje podnosi kortikal na kost femura odrasle osobe prije nastanka preloma, po Reilly-u, pri djelovanju sile kompresija, je $205 \pm 17,3 \mathrm{Mpa}$ ili sila smicanja je $71 \pm 2,6$ Mpa. Maksimalno opte rećenje prije preloma femura pri dejstvu sile tenzije je $53 \pm 10,7 \mathrm{Mpa}$ ili sile kompresija je $131 \pm 20,7 \mathrm{Mpa}^{\mathrm{B}}$

Energija se širi kroz kost kao talas, a brzina tog talasa opteré́uje kosti oko $3000 \mathrm{~m} / \mathrm{s}$. Potrebno je $15 \mathrm{~J}$ energije za frakturu dijafize tibije ili femura kod odrasle osobe. Energija oslobođena kod osoba od $70 \mathrm{~kg}$ pri padu na zemlju iz stojećeg stava je oko 500 J. Sposobnost apsorpcije energije imaju ekcentrične kontrakcije mišića i deformacijemekih tkiva koje sprečavaju nastanak fraktura u beznačajnim, manjim padowima kod mladih, dok kod starijih osoba to nije moguce. ${ }^{9}$

Posljednja u nizu „bioloških" noviteta AO skupine iz Davosa je LCP ploča, urađena po po principima ograničene kontaktne površne s korteksom. ${ }^{10}$ Za novodizajniranu pločı karakterističan je dvojni oblik rupa i mogućnost korišstenja dvije vrste vijaka. Klasičnim vijcima i otvorima postiže se kompresivna dinamička osteosinteza. Odmah uz klasične, postavljeni su i пагеzani otvori. Uvrtanjem novih vijaka u njih, ploča postaje unutarnji fiksator, a fragmenti se fiksiraju po prinicipu elastične stabilne osteosinteze. LCP ploča-fiksator se može aplicirati na mjesto preloma klasičnom ili minimalnom invazionon osteosintezon. ${ }^{10}$

Onur Başc je na dvadesetjednom lijevon femuru od kadavera ispitivao biomehaničku stabilnost prelona dijafize femura po AO klasifikaciji Tip A1, A2, A3 sa LIN i LCP pločom. Prvu grupu sačinjavalo je sedam femura stabilizovanih sa LCP pločom, drugu grupu stabilizovamu sa LDN takođe sedam, dok je treća grupa od sedam femura stabilizovana sa LCP i LIN. Grupa stabilizovana sa LCP bila je relativno otporna na torziono opterécenje ispitivanja $(\mathrm{p}=0,949)$, u odnosu na grupu stabilizovanu LDN koja je bila relativno otpornija na aksijalnu kompresiju $(\mathrm{p}=0,225)$ u odnosu na grupu stabilizovanu sa LCP. Treća grupa bila je značajno otpornija u odnosu na drugu grupu u aksijalnom $(\mathrm{p}=0,003)$ i torzionom $(\mathrm{p}=0,008)$. Zahvaljujući visokoj biomehaničkoj stabilnosti koja onogućava ranu mobilnost, LCP i LIN u kombinaciji mogli bi biti izbor liječenja kod komplikova nilı A3 osteoporotičniłs preloma distalnog femura kod mladih i odraslih osoba. ${ }^{11}$

Bunyamin A. i sar. su na tibiji ovce ispitali biomehaničke osobine stabilnosti uzdužnih i kosih preloma. Preloni su stabilizovani ravnim i spiralnim DCP. Tako stabilizovan prelon bio je izložen dejstvı sila na aksijalnu kompresiju, sevijanja i torziju. Postoji statistički značajna razlika koja potvrđuje da DCP daje bolju stabilizaciju. Spiralna ploča pri dejstvu sila torzije ina veću snagu i otpornost od DCP ploče. In vitro biomehanička istraživanja pokazala su različite rezultate pod različitim opterećenjima. Trenutne biomehaničke analize mogu u bliskoj budućnosti podstaći korištenje spiralnih DCP za stabilizaciju preloma. ${ }^{12}$

Eksperimentalna ispitivanja o uticaju opterécenja i pomjeranje fragmenata femura stabilizovanim пaboranim i neboranim Kuncher-on sprovedena su na modeh femura.Grupa A stabilizovana je neboranim Kuncherom, a u grupama B i C postavljen je borani Kuncher kod kojeg je slobodan prostor ispod trochanter major izmedu klina i korteksa iznosio $100 \mathrm{~mm}$. Na osnovi ispitivanja došlo je do saznanja da je maksimalna vrijednost ponjeranja u frontalnoj ravni distalnog femura 1,86 mm, a minimalno u sagitalnoj ravni proksimalnog femura $0,08 \mathrm{~mm}$. Dobijene vrijednosti ni u jednoj ravni ne prelaze prihvatljivo ponjeranje do $3 \mathrm{~mm}$ koje bi onemogućilo koštanu konsolidaciju. ${ }^{13}$

Sanacija preloma uslovljena je kontrolisanim aksijalnim opterécenjem i mikropokretima. Koliko je to aksijalno opterécenje a koliki mikropokreti još nije jasno definisano. Kako prelon zarasta, bilo bi idealno da raste opteré́enje same kosti, a da se opterécenje na osteosintetski materijal smanjuje. Ta postepena promjena aksijalnog opterećenja i mikropokreta može se postići korištenjem pravovremene dinamizacije sa DCP, LCP, IFM i LIN.

\section{Zaključak.}

U softverski program CATIA i ANSYS unesene su vrijednosti za: elastičnost, visokoelastičnost, plastičnost, čvrstoća, tvrdoća, žilavost, vibracija i torzija kosti. Ovakav model onogućuju identične bionehaničke uslove za sva ispitivanja ispitivanog osteosintetskog materijala. 
Rezultati ispitivanja biomehaničke stabilnosti na osnovı diletacije na mjestu preloma na SCA simulatoru pokazuju da je na prvon mjestu LDN sa koeficijentom zbiraKLIN $=0,195^{\circ}$, a zatim slijedeDCP sa $\mathrm{KDCP}=0,1970$, IFM sa KIFM=0,2238 i LCP sa Ko,2394.

LDN ima neznatnu prednost u liječenju dijafizarnih poprečnił, spiralnih i kominutivnih preloma u odnosu na DCP,IFM i LCP.

Rad je nastao kao rezultat istraživanja u okviru naučnoistraživačkog projekta broj 150414/2015 pod nazivon „Komparacija biomehaničke stabilnosti:antirotacionog intramedularnog klina,dinamičke kompresivne ploče,dinamičko zaključane ploče i unutrašnjeg fiksatora po Mitkoviću", koji je realizovan uz finansijsku podršku Ministarstva nauke i tehnologije u Vladi Republike Srpske.

\section{Reference}

1. Predrag Grubor, Milan Grubor: "Results of Application of Eexternal Fixation with Different Types of Fixatorg ", Srp. Arh Celok Lec. 2012, May-Jum.140 (5-6), 332-338.

2. Müller, M. E., Allgöwer, M., Schneider, R., Willenegger, H., Udžbenik osteosinteze, Jugoslavenska medicinska naklada, Zagreb, 1981.st.24

3. Korner, J. et al.: A biomechanical evaluation of methods of distal humerus fracture fixation using locking compression plates versus conventional reconstruction plates. I Orthop Trauma, 18 ( 5 ), 2004, 286-293.

http//dx.doi.org/10.1097/00005131-200405000-00004 PMid: 15105750

4. Mitkovic M, Bumbasirevic M, Golubovic Z, Mladenoric D, Milenkovic S, Micic I. New biological methodof internal fixation of the femur. Acta Chir Jugosl. $2005 ; 52(2): 113-6$. http://dx. doi.org/10.2298/ACIo502113M

5. Wali MG, Baba AN, Latoo IA, Bhat NA, Baba OK, Sharma S: Internal fixation of shaft humerus fractures by dynamic compression plate or interlocking intramedullary nail: a prospective, randomised study. Strategies Trauma Limb Reconstr. 2014
Now 943$) \div 33-40$.

http://dx.doi.org/10.1007/g11751-014-0204-0 PMid:25408496 PMCid:PMC4278972

6. Sabalić, S., Kodvanj, J., Pavić, A.: Comparative study of three models of extra-articular distal humerus fracture osteosynthesis using the fimite element method on an osteoporotic computational model. Injury, Int. $44 \mathrm{~S}_{3}, 2013, \mathrm{~S}_{54}$-S61.

7. Predrag Grubor: Osnovi biomehanike lokomotornog sistema i implantata, Glas Srpske, Bamja Luka 2003.

8. Reilly DT, Burstein AH (1975) The elastic and ultimate properties of compact bone tissue. J Biomech 8:393-405. http//dx. doi.org/10.1016/0021-9290(75)90075-5

9. Gautier, E., Perren, S.M., Cordey, J.: Effect of plate position relative to bending direction on the rigidity of a plate asteosynthesis. A theoretical analygis. Injury., 31 Suppl $3,2000, \mathrm{C}_{4} 4-20$. http//dx.doi.org/10.1016/So020-1383600)80027-3

10. Bunyamin Aksakal, Murat Gurger, Yakupsay, Erhan Yilmaz: Biomechanical comparison of straight DCP and helical plates for fixation of transrerse and oblique bone fractures, Acta of Bioengineering and Biomechaniog, Vol. 16, No. 4, 2014. PMid:25597271

11. Onur Başcı, Ahmet Karakaşlı, Erdem Kumtepe, Ortaç Güran, Hasan Havtç̣oğlu, Onur Başcr, Ahmet Karakaşl, Erdem Kumtepe, Ortaç Güran, Hasan Havitçığlu:Combination of anatomical locking plate and retrograde intramedullary nail in distal femoral fractures: comparison of mechanical stabilitity, Eklem Hastallk Cerrahisi, $2015 \% 26(1) \div 21-26$.

http://dx.doi.org/10.5606/ehe.2015.06 PMid:25741916

12. Bunyamin Aksakal, Murat Gurger, Yakupsay, Erhan Yilmaz: Biomechanical comparison of straight DCP and helical plates for fixation of transverse and oblique bone fractures, Acta of Bioengineering and Biomechanics, Vol. 16, No. 4, 2014 . PMid 25597271

I3. A.Kajzer, W. Kajzer, J. Marciniak, Expandable intramedullary nail - experimental biomechanical evaluation, Archives of Materials Science and Engineering $41 / 1$ (2010) 45-52. 


\section{Examination of Stability of Osteo-Syntetic Matherial By Software Bone Stimulator}

\section{ABSTRACT}

Introduction. Softwaresimulator model (SSM) is a computer program written in one of the many programming languages. Based on the given input data on mathematical biomechanical model of bones and on various osteosynthesis material models, it calculates and provides the required output results of dilatation $(\mathrm{mm})$ at the site of the fracture inrelation to the applied axial and a lateral force(N).

Aim of the study. To examine the budget voltage and deformation of the compressive forces and bending simulator software model in dynamic compression plate (DCP), dynamic locked extension compression plate (LCP), locked intramedullary nail (LIN) and Mitković internal fixator (MIF).

Material and methods. CATIA software was used to create a 3D model of the DCP, the LCP, MIF, LIN and for the calculation of stress and strain for the pressure and bending, ANSYS (SCA) software was used. The tested material was loaded by compression forces up to 500 Nand bending forces up to $250 \mathrm{~N}$.

Results. Results of biomechanical tests on SCA showed that, according to biomechanical stability, LIN was in the first rank, with coefficient ranking KLIN=0.1950. Subsequently, there was TDCP with KDCP=0.1970, MIF with KMIF $=0.2238$ and LCP with KLCP=0.2394.

Discussion. Based on the input data, mathematical model is formed and it uses the entered data, calculates and edits the required results. There is a tendency in today's world to make the standardization of software testing, so that tested results could be easily applied and interpreted in scientific research purposes.

Conclusion. First in rank by biomechanical stability was $L I N$ with coefficient ranking $K L I N=0.1950$. Subsequently, there was $\mathrm{DCP}$ with $\mathrm{KDCP}=0.1970$, MIF with $\mathrm{KMIF}=0.2238$ and $\mathrm{LCP}$ with $\mathrm{KLCP}=0.2394$.

Key words: biomechanics, dynamiccompressionplate, CATIA software, ANSYS. 